\title{
Enigma variations on the nuclear stage
}

\section{Copenhagen}

A play by Michael Frayn

Performed at the National Theatre, London Methuen: 1998. 128pp. £6.99 (pbk)

\section{Michael Berry}

In Copenhagen, Michael Frayn re-creates one of the more mysterious episodes of the Second World War, when Werner Heisenberg travelled to German-occupied Denmark in 1941 to visit his fellow physicist Niels Bohr. Why did he go there?

Historians - as well as the protagonists themselves, with their faulty and shifting memories - have long puzzled over Heisenberg's motives. Did he seek to enlist Bohr's assistance in developing a German nuclear bomb? Was he pumping Bohr for information about a possible parallel programme by the Allies? Was he alerting Bohr to the existence of the German programme, in the hope that Bohr would provoke the Allies to accelerate their own programme? Was he seeking a reason to delay, or even sabotage, the German nuclear effort? And why did the German programme fail? Was it through rivalry and division of resources between competing teams, or because a crucial neutron diffusion rate was wrongly assumed instead of being calculated?

In the play, these possibilities are explored in detail and with sensitivity, concentrating on the contrapuntal relationship between the two physicists' personalities, their careers, and their scientific styles. Bohr, 16 years Heisenberg's senior, initiated the modern theory of the atom in 1913, with his proposal that the energies of electrons in atoms are restricted by quantum rules similar to those that Planck and Einstein had applied to light. This was not only bold but outrageous, because it had no basis in theoretical physics - indeed, it flatly contradicted the established 'classical' physics of the day.

Twelve astonishing years followed, in which the most intense concentration of scientific effort was devoted to the search for the fundamental quantum theory underlying Bohr's atom. An important centre of that research was Bohr's newly established institute in Copenhagen. He imported a stream of brilliant young physicists, and sought unremittingly to uncover the physical significance of their theories and formalisms. This led him into philosophy, and to his principle of complementarity. His style was slow, tentative, almost inarticulate, repeatedly redrafting his papers in the hope of reaching a version that matched what he was groping for.

Heisenberg, competitive, insecure, barely into his twenties when he went to Copenhagen, was instantaneous in his responses, diamond-hard in the precision of his

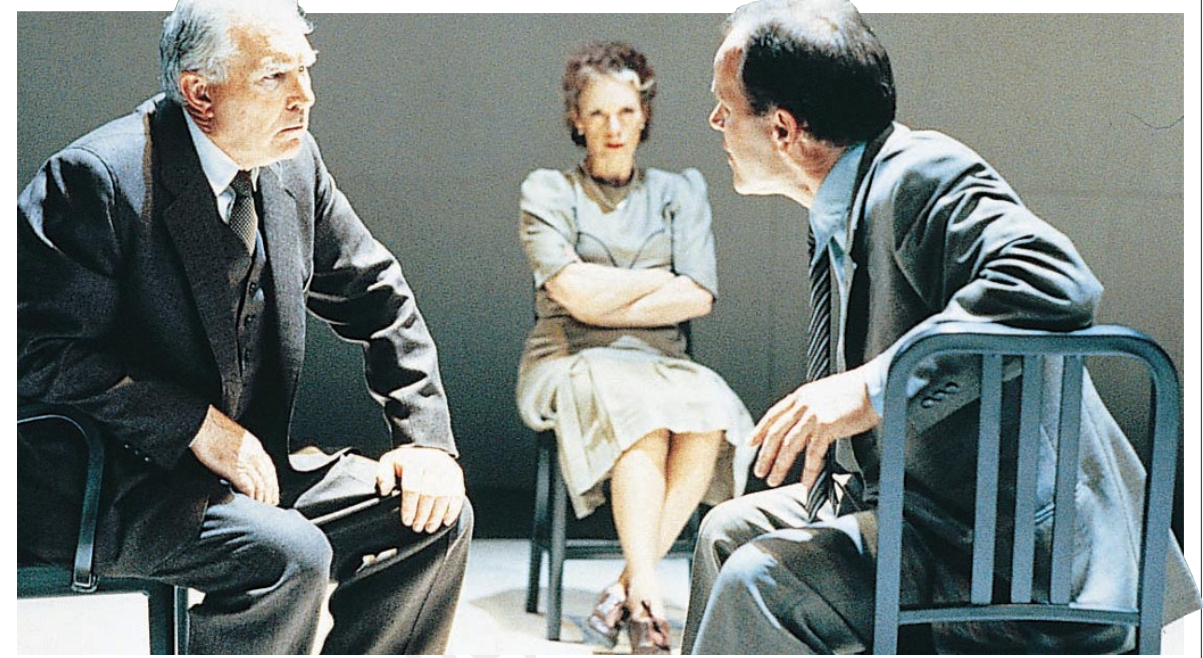

Meeting of minds: Burke (left), Kestelman and Marsh succeed in the fusion of science and drama.

thought. He occupied himself with mathematical formalism rather than wordy interpretations. It was he who reached the first consistent quantum mechanics: spare, algebraic, a landscape alien to theoretical physicists yet capable of reproducing all the hitherto baffling experimental observations on atoms. Complementing Bohr's complementarity was Heisenberg's uncertainty principle, a precise statement of the limits within which a particle's position and motion can be known.

The structure of the play mirrors these contrasts. Bohr appears mumbling, reflective, but with a simple goodness ("I don't think anyone has yet discovered a way you can use theoretical physics to kill people") and clear moral insight; Heisenberg, swifttongued but morally ambiguous. The 1941 meeting is repeatedly re-enacted and revisited, echoing Bohr's repeated redraftings, in attempts to get at what really happened. As each dilemma gets focused on, another recedes, vague, into a mist.

Underlying the momentous events that followed the Copenhagen encounter are facts about atomic nuclei, understandable only in terms of quantum physics. Frayn does a splendid job of explaining these subtle and tricky matters, in some detail yet without technicalities. Through the exchanges of the protagonists, we get clear accounts of fission, the production of nuclei, chain reactions (where the play as staged corrects an arithmetic error in the published version), the important distinction between slow and fast neutrons, diffusion rates, and quantum uncertainty and interference.

On a stage bare but for three chairs, our attention is gripped and held by three actors: Bohr, played by David Burke, Heisenberg by Matthew Marsh, and Bohr's wife Margrethe by Sara Kestelman. Margrethe is the chorus, mercilessly exposing Heisenberg's evasions and Bohr's good-natured, even fatherly, indulgence towards his former colleague. Marsh and Burke bring out beautifully the obvious affection between the two very different men, strained to the utmost by the excruciatingly hard times - and not helped by Heisenberg's clumsy invitation to the Bohrs to make use of his ski-hut in Bavaria, apparently forgetting that Bohr was half-Jewish.

With Copenhagen, Frayn helps to create a genre, alongside Tom Stoppard, with Hapgood, inspired by quantum mechanics, and Arcadia, based on chaology, and Mike Maran, with Surely You're Joking, Mr Feynman, about that unique and colourful physicist. This acceptance of science as a legitimate subject for dramatization, rather than something separate and technical, is both welcome and overdue. In human culture, as with nuclei, fusion is more powerful than fission but harder to achieve.

Michael Berry is in the Physics Department, University of Bristol, Bristol BS8 1TL, UK.

\section{Myths thatwoñ̃die}

\section{Frankenstein's Footsteps: Science,} Genetics and Popular Culture

by Jon Turney

Yale University Press: 1998. 320pp. $£ 19.95, \$ 30$

\section{Roslynn Haynes}

"What terrified me will terrify others", wrote Mary Shelley of the nightmare that allegedly provided the inspiration for Frankenstein. Nearly two centuries later her words remain uncomfortably prescient. The name of her protagonist and the image of his Monster are ever available as shorthand to evoke the whole package of emotional reactions to perceived hubris - from guilty fascination to fear and 
moral revulsion - with which Western culture periodically frightens itself.

The locus of our concern may have moved from the electrical stimulation of corpses, through vivisection and eugenics, to the Human Genome Project, cloning and experiments with recombinant DNA, but we have failed to come up with new scientific myths in which to express it.

Jon Turney's comprehensive study of the public face of biology since Shelley's time shows how her creation has never let go its power, even stranglehold, over popular imagination. The literary inheritance of Frankenstein has been well documented before. But Turney's important contribution lies, first, in integrating the fictional images with their counterparts in film and journalism and, second, in attempting to assess the appropriateness of the myth today, in relation to what Dorothy Nelkin and Susan Lindgee have called the "narratives of genetic essentialism".

Formerly science editor of the Times Higher Education Supplement and currently senior lecturer in science communication at University College London, Turney is admirably qualified to trace journalists' responses to the intellectual and technological leaps biologists have made in this century. Drawing on sources as diverse as reports in Nature, tabloid headlines and cartoons, he demonstrates how consistently Frankenstein, and the related mad-scientist script, have been invoked. In the process he also presents us with an extremely readable, if selective, history of the discipline and frequently points to the disparity between popular impressions of biological landmarks and the views of the scientists concerned.

On the one hand, Turney shows the inadequacy of the stereotyped response to technological breakthroughs. The furore greeting the birth of Louise Brown, the world's first 'test-tube' baby, now seems astonishing, generating fears that have proved groundless. Perhaps, in a decade, the doomsaying response to Dolly, the cloned sheep, will appear equally overblown. But on the other hand, the bland dismissal by many scientists of all social concerns as mere anti-scientism, as 'genetic pornography', is equally blinkered.

More sinister than the facile name-calling is the cynical manipulation of public anxiety. A notable case documented here was the moratorium declared in 1974 by molecular biologists on their own recombinant DNA experiments. By this seemingly responsible initiative, the signatories not only softened public opinion but retained control over both the duration of the moratorium and the boundaries to the ensuing discussion. The focus was effectively and conveniently limited to technological safety measures rather than embracing issues of social and moral responsibility that were the real crux of popular concern.

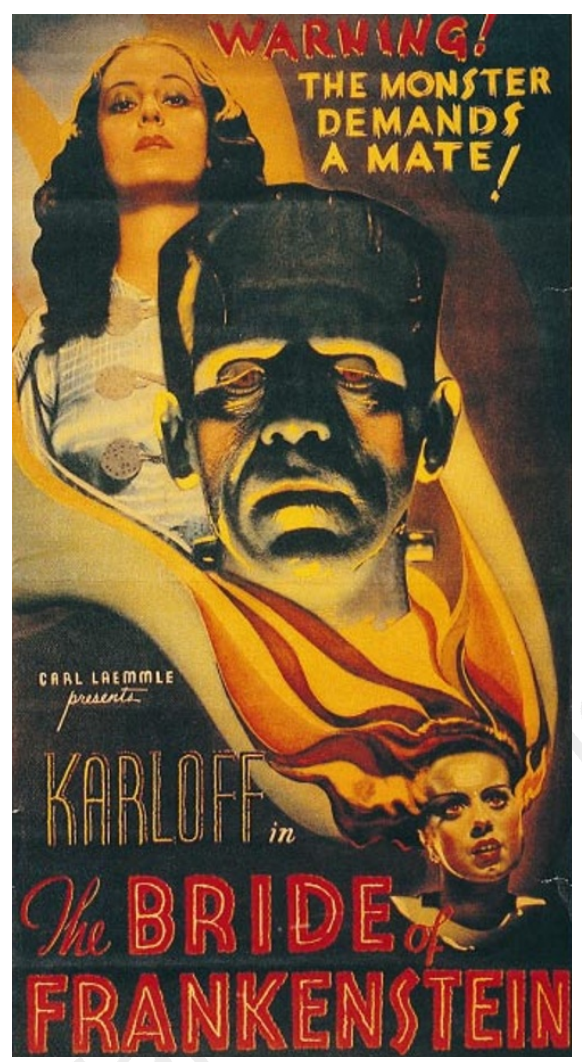

No fear: with hindsight, public anxiety about biological breakthoughs may seem unfounded.

The acknowledged inspiration for Frankenstein's Footsteps was Nuclear Fear (Harvard University Press, 1988), Spencer Weart's history of images that attempted to uncover the origins of our attitudes to nuclear physics, and a particularly interesting aspect of Turney's study is the juxtaposition of popular responses to biology and physics. During the Cold War, atomic physicists were designated the heirs of Frankenstein, but Turney argues that biology remains the more dangerous, more invasive discipline.

Where physics is largely concerned with understanding and with theory, biology openly aligns itself with the Baconian aspiration of manipulating knowledge to "the effecting of all things possible". Indeed, biologists have frequently been the ones to introduce provocative rhetoric, from Jacques Loeb and Alexis Carrel's self-publicity at the beginning of the century about their imminent 'creation of life' in the laboratory, to Francis Crick's emotive phrase for molecular biology as an exploration of "the borderline between the living and the dead", with its echo of Frankenstein's words. Michael Mulkay's recent analysis of the British parliamentary debate over embryo research shows that, while non-scientists rarely invoked Frankenstein or his successors, scientists themselves introduced such references to the record by claiming that their opponents were unduly influenced by them.

Although he strives to be factual and unbiased throughout, Turney seems to suggest that many of the fears voiced by the 'uninformed' public are not entirely unfounded. For a century biologists have a sad record of treating society with contempt. His conclusion is that, rather than accusing their lay contemporaries of being fixated on the Frankenstein cliché, scientists themselves need to be more innovative and serious in telling new and more complex stories. These could help us move beyond the false, polarizing alternatives of closed minds and created monsters.

Although this book necessarily concentrates on written texts, the black and white illustrations form an important adjunct, indicating the extent and flexibility of the imagery surrounding the subject. For example, a recent cartoon from The Guardian shows a figure who not only bares his manly chest but parts the flesh like a model in a classical anatomy text, to reveal a bar code representing his DNA analysis - the ultimate identity index. Frankenstein's Footsteps should be read by all who are concerned about the social and ethical implications of DNA experimentation and, even more importantly, by those who are not.

Roslynn D. Haynes is the author of From Faust to Strangelove: Representations of the Scientist in Western Literature (John Hopkins University Press, 1994). She is in the School of English, University of New South Wales, Sydney, NSW 2052, Australia.

\section{Getting to grips with the solid Earth}

\section{Principles of Geophysics}

by Norman H. Sleep and Kazuya Fujita Blackwell Science: 1997. 586pp. £39.50, $\$ 72.95$

\section{Fundamentals of Geophysics}

by William Lowrie

Cambridge University Press: 1997. 354pp.

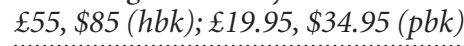

\section{Jon Bull}

Geophysics is a broad term that encompasses all aspects of the Earth system. These textbooks focus on "solid earth geophysics" but also have chapters on planetology. Both aim to be comprehensive supporting texts for university courses; they are similar in scope and range to the widely used The Solid Earth by C. M. R. Fowler (Cambridge University Press, second edition due summer 1999).

Principles of Geophysics, by Norman H. Sleep and Kazuya Fujita, is well written, adopts a novel approach, and concentrates on the underlying physics. The level of difficulty increases through the book, but each chapter has a clearly written introduction in which the key physical concepts are outlined. Most aspects of solid Earth geophysics are dealt with, but in covering such a vast range of material the treatment is necessarily 